\title{
Anthocyanins as a corrosion inhibitor for 2024-T3 aluminum alloys: a study of electrochemical behavior
}

\author{
A. Petersen, ${ }^{\text {a }}$ S.R. Rodrigues, ${ }^{\text {a }}$ V. Dalmoro, ${ }^{\text {a }}$ T. Falcade ${ }^{\mathrm{a}}$ \\ and S.M. Tamborim ${ }^{\mathrm{a}}$ * \\ "Post-Graduate Program in Chemistry, Federal University of Rio Grande do Sul, \\ Avenida Bento Gonçalves, 9500, Porto Alegre, Brasil \\ *E-mail: silvia.tamborim@ufrgs.br
}

\begin{abstract}
Grape anthocyanin efficiency as a corrosion inhibitor for 2024-T3 aluminum alloy was evaluated by electrochemical techniques such as, electrochemical impedance spectroscopy and cathodic and anodic potentiodynamic polarization. The inhibitor behavior for 2024-T3 aluminum alloy was investigated in $800,1000,2000,3000,5000$ and $7200 \mathrm{ppm}$ of the grape anthocyanin solution in the presence of $0.025 \mathrm{~mol} \cdot \mathrm{L}^{-1} \mathrm{NaCl}$. According to electrochemical impedance spectroscopy results, the measured point dispersion in the low frequencies region decreased when the 2024-T3 aluminum alloy immersion time in the grape anthocyanin solution increased from $1 \mathrm{~h}$ to 3 days. It was also observed for samples after 3 days immersion that there was a reduction in the inductive behavior in the same region, and a considerable increase in the polarization resistance and inhibition efficiency for the $1000 \mathrm{ppm}$ grape anthocyanin sample. Under anodic and cathodic polarization a generally better performance was also observed in the anticorrosive properties as potential and current corrosion and anti-corrosion protection efficiency for the above mentioned concentration sample. The grape anthocyanin adsorption characteristics, on the AA2024T3 indicated similar behavior to Langmuir isotherm.
\end{abstract}

\section{Keywords: anthocyanins; corrosion inhibition; aluminium alloy.}

Received: May 3, 2017. Published: June 23, 2017.

doi: $\underline{10.17675 / 2305-6894-2017-6-3-5}$

\section{Introduction}

The known hazardous effects of most synthetic organic inhibitors and restrictive environmental regulations have prompted researchers to focus on the need to develop cheap, non-toxic and environmentally benign natural products as corrosion inhibitors. In that sense, natural products such as compounds extracted from leaves, barks, fruits or seeds have been widely reported by several authors as aluminum and aluminum alloy corrosion inhibitors [1-7]. The efficiency of natural compounds as corrosion inhibitors depends on the chemical composition which can be tannins, alkaloids, carbohydrates, phenolic compounds and protein [8]. Generally, those compounds contain at least one polar group with an atom of nitrogen or sulfur and moieties consisting of triple or conjugated double 
bonds or aromatic rings. Therefore, its molecular and electronic structures are similar to those of conventional organic inhibitor molecules [9].

Among the various compounds that are extracted from plants and fruits are the anthocyanins (derived from Greek anthos $=$ flower and kianos = blue) [10]. The anthocyanin skeletal structure contains 15 carbon atoms [11] and absorb strongly in the visible region of the spectrum, giving us an infinity of colors that depend on the environment [12]. Fruits anthocyanins are derived mainly from six anthocyanidins: pelargonidin, cyanidin, delphinidin, peonidin, petunidine and malvidin. There is a huge variety of anthocyanins in nature, so it is possible to mention some differences in the number of hydroxyl groups, the methylation degree of those groups, the nature and number of sugar bound to the molecule and the position of those bonds, as well as the nature and number of aliphatics and/or aromatics bound to the sugar(s) in the anthocyanin molecule [10-12].

Furthermore, to our knowledge there are no reports about the corrosion inhibition effects of anthocyanin on metals. Thus, the aim of the present study is to evaluate the inhibitory action of grape anthocyanin in $0.025 \mathrm{~mol} \cdot \mathrm{L}^{-1} \mathrm{NaCl}$ on corrosion behavior of aluminum alloy 2024-T3. The anthocyanin corrosive inhibition was examined by polarization and electrochemical impedance spectroscopy (EIS) techniques and the influence of anthocyanin on AA2024 surface morphology and topology was investigated by scanning electron microscopy (SEM), Energy Dispersion Spectroscopy (EDS) and atomic force microscopy (AFM) analysis.

\section{Experimental Procedure}

This study was performed with grape anthocyanin from Chr. Hansen Ind. \& Com. Ltda. and with 2024-T3 aluminum alloy from Aeromot whose composition is presented in Table 1.

Table 1. Composition of the 2024-T3 aluminum alloy.

\begin{tabular}{ccccccccccc}
\hline $\begin{array}{c}\text { Chemical } \\
\text { composition }\end{array}$ & Cu & Mg & Si & Fe & Mn & Cr & Zn & Ti & Others & Al \\
\hline$\%$ (weight) & $3.8-4.9$ & $1.2-1.8$ & 0.5 & 0.5 & $0.3-0.9$ & 0.1 & 0.15 & 0.15 & 0.15 & rem. \\
\hline
\end{tabular}

Sodium chloride (Merck) was used to prepare the electrolyte solutions at the concentration of $0.025 \mathrm{~mol} \mathrm{~L}^{-1}$. Grape anthocyanin (Hansen) was evaluated as an inhibitor at concentrations of $800,1000,2000,3000,5000$ and $7200 \mathrm{ppm}$.

\subsection{Preparation of working electrodes}

The surface of the planar specimens of size $2 \mathrm{~cm} \times 3 \mathrm{~cm}$ and thickness of $1 \mathrm{~mm}$ was prepared by grinding it with silicon carbide paper up to grade number 1200 followed by washing it with distilled water commercial alcohol from Zeppelin, and drying it under a 
hot air stream. After that an area with $1 \mathrm{~cm}^{2}$ was exposed using neutral Brascoved silicone from Brascola to delimit the area.

Measurements were made after the immersion of electrodes for different lengths of time times - from $1 \mathrm{~h}$ to 3 days - in the chloride solutions containing or not anthocyanin.

\subsection{Electrochemical measurements}

A three-electrode system was used: a working electrode with $1 \mathrm{~cm}^{2}$ of exposed area (2024T3 aluminum alloy); a reference electrode (Saturated Calomel Electrode - SCE) and, a platinum counter electrode. The electrochemical measurements were performed using a potentiostat ( $\mu$ Autolab III, Echo Chemie, The Netherlands) coupled to a frequency response analyzer (FRA 2), from Metrohm. The Electrochemical Impedance Spectroscopy (EIS) measurements were performed in potentiostatic mode at the open circuit potential, OCP. The amplitude of the EIS perturbation signal was $10 \mathrm{mV}$, and the frequency range studied was from $100 \mathrm{kHz}$ to $10 \mathrm{mHz}$. The anodic and cathodic polarization curves were recorded at a scan rate of $2 \mathrm{mV} \mathrm{s}^{-1}$. The cathodic curves were measured from the open circuit potential to $-0.8 \mathrm{~V}$ potential while the anodic curves were measured from open circuit potential to $+0.5 \mathrm{~V}$.

\subsection{Scanning Electronic Microscopy and Energy Dispersion Spectroscopy}

Scanning Electron Microscopy (SEM) and Energy Dispersion Spectroscopy (EDS) were performed using a Zeiss, EVOSO apparatus. The sample was prepared following 3 steps:

(i) 3 days of immersion in $0.025 \mathrm{~mol} \cdot \mathrm{L}^{-1} \mathrm{NaCl}$ in presence and absence of the $1000 \mathrm{ppm}$ grape anthocyanin;

(ii) Drying under a hot air stream;

(iii) Metallizing with gold.

\subsection{Atomic Force Microscopy}

The atomic force microscopy (AFM) measures were performed in an Agilent 5500 apparatus in intermittent contact mode at a scanning speed of $10 \mu \mathrm{m} \cdot \mathrm{s}^{-1}$. The samples were prepared according to previously mentioned SEM/EDS analysis, but the samples were used without metallization.

\subsection{UV-VIS Absorption Spectroscopy}

The anthocyanin solution absorbances were measured in a quartz cuvette in a Pro-Analise $\mathrm{V}-1100$ spectrophtometer at $550 \mathrm{~nm}$. The following procedures were performed:

(i) The absorbance of $0.025 \mathrm{~mol} \mathrm{~L}^{-1} \mathrm{NaCl}$ solutions containing 100, 500, 800, 1000, $2000,3000,5000$ and $7200 \mathrm{ppm}$ grape anthocyanin was measured after $1 \mathrm{~h} \mathrm{of}$ preparation;

(ii) After that, specimens of AA2024-T3 aluminum alloy were prepared according to item 2.1 (however this preparation was done without delimiting the area) and previously 
weighed, and after which they were immerged for 3 days in the solutions mentioned in item(i);

(iii) After that immersion time, the solution absorbance was determined for the samples cited in (i).

According to Lambert-Beer Law the anthocyanin sample absorbance is proportional to the concentration [13]. Thus the decreasing absorbance of the aluminum alloy after 3 days was related to the adsorption of the anthocyanin on the AA2024-T3 aluminum alloy surface. Hence, the concentration of the anthocyanin adsorbed on AA2024-T3 aluminum alloy surface was calculated, in $\mathrm{mg} \cdot \mathrm{L}^{-1}$, by diminishing the initial anthocyanin concentration from that which remained after 3 days of immersion as presented in equation (1):

$$
C_{\text {adsorbed }}=C_{\text {initial }}-C_{\text {remaining }}
$$

Considering the anthocyanin adsorbed concentration on the 2024-T3 aluminum alloy surface calculated above (1), it was possible to determine the amount of inhibitor adsorbed in the equilibrium state $\left(Q_{\mathrm{e}}\right)$, according to equation (2):

$$
Q_{\mathrm{e}}=\frac{C_{\text {adsorbed (adsorbent) }}}{\text { specimen weight (adsorbate) }}
$$

\section{Results and Discussion}

\subsection{Electrochemical impedance measurements}

After $1 \mathrm{~h}$ of immersion in chloride solutions containing different concentrations of anthocyanins EIS measurements are performed (Figure 1).

(A)

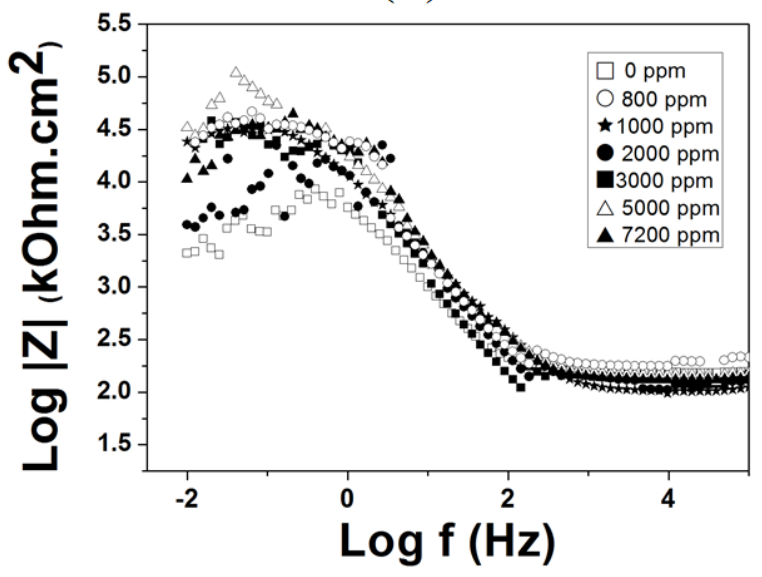

(B)

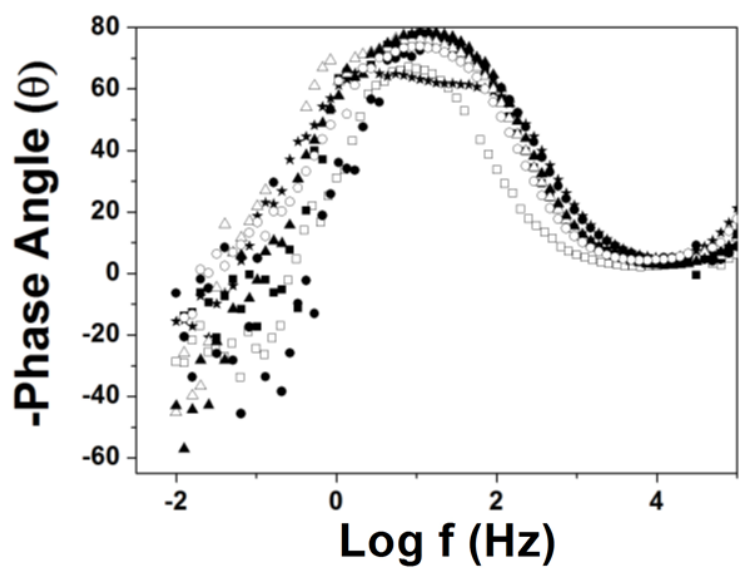

Figure 1. 2024-T3 aluminum alloy Bode diagrams for $1 \mathrm{~h}$ of immersion in $0.025 \mathrm{~mol} \cdot \mathrm{L}^{-1}$ $\mathrm{NaCl}$ with diferent anthocyanin concentrations. 
The Bode spectrum at $1 \mathrm{~h}$ of immersion of aluminum alloy in chloride solution shows one time constant at medium frequency $\left(10^{-1} \mathrm{~Hz}\right)$ and high dispersion of points in the region of the medium to low frequencies, characterizing an inductive process. On the other hand, the samples immersed in anthocyanin solutions present a broader relaxation process ca. $\left(10^{-1.5} \mathrm{~Hz}\right)$, which may be related to the dynamics of the process of anthocyanin adsorption on the alloy surface, followed by the inductive point at low frequency. It is also observed that the onset of inductive behavior shows a delay in the presence of $1000 \mathrm{ppm}$ of anthocyanin $(0 \mathrm{ppm}-0.251 \mathrm{~Hz}, 1000 \mathrm{ppm}-0.051 \mathrm{~Hz})$, plausibly due to adsorption of anthocyanin on the metal surface, i.e., it acts as a protective species.

There is no consensus in the literature concerning the appearance of inductive points on EIS spectra. According to Tribollet and Orazen the inductive process is related to specific adsorption on a metallic surface, such as electrolyte species [14]. For aluminum and aluminum alloys exposed to chloride solution some research results have been attributed to surface or bulk relaxation of species in the oxide layer related to active dissolution sites taking into account the damaged areas of the film $[15,16]$. Chloride ions are chemisorbed onto the oxide surface and act in aluminum dissolution via the formation of oxychloride complexes [17].

In the present study, it is plausible to assume that a competition occurs between chloride ions and anthocyanin for the aluminum surface sites. Since the aluminum alloy samples immersed in solution containing anthocyanins present higher impedance modulus values than panels in chloride solution, the anthocyanins were probably adsorbed on AA2024 surface, the chloride adsorption was reduced, and the aluminum alloy corrosion was reduced.

On the other hand, the similar nature of impedance diagrams obtained in the absence and presence of corrosion inhibitors after $1 \mathrm{~h}$ immersion time reveal that the addition of inhibitors does not change the mechanism for the dissolution of AA2024-T3 aluminum alloy in $\mathrm{NaCl}$ [18-20], i.e., it is not directly involved in the electron transfer process. Nevertheless, this adsorption process can modify the product on the surface alloy and the structure of corrosion products, slowing down the electron transfer reactions.

It is essential to monitor the inhibitor action over time in order to evaluate its efficiency. Thus, chloride solutions containing $0,800,1000$ and $2000 \mathrm{ppm}$ of anthocyanin were examined by electrochemical impedance spectroscopy after 3 days of immersion (Figure 2). These anthocyanin concentrations were chosen due to better performance at $1 \mathrm{~h}$ of immersion associated with the fact of lower inhibitor consumption.

The impedance diagram at 3 days for AA2024 samples in chloride solution displays a single capacitive loop represented by a slightly depressed semi-circle follow by a tail at low frequency. This time constant at high frequency is related to the properties of the oxide aluminum barrier layer and the process at low frequency suggests a controlled mass transfer process transport through the pores of pits and/or of corrosion products [21].

Different Nyquist plots are obtained for the samples in anthocyanin solution, i.e., the relaxation process at low frequency is not detected. Furthermore, for aluminum alloy in 
chloride solution with $1000 \mathrm{ppm}$ of anthocyanin two capacitive arcs can be noted. The diameter of the capacitive loop increases considerable at $1000 \mathrm{ppm}$ of anthocyanin. This increase indicates adsorption of inhibitor molecules on the metal surface and the ability of the anthocyanin to hinder the corrosion process [6]. In this sense, it is plausible to assume that the adsorption of protective molecules occurred efficiently at $1000 \mathrm{ppm}$ of anthocyanin.

(A)

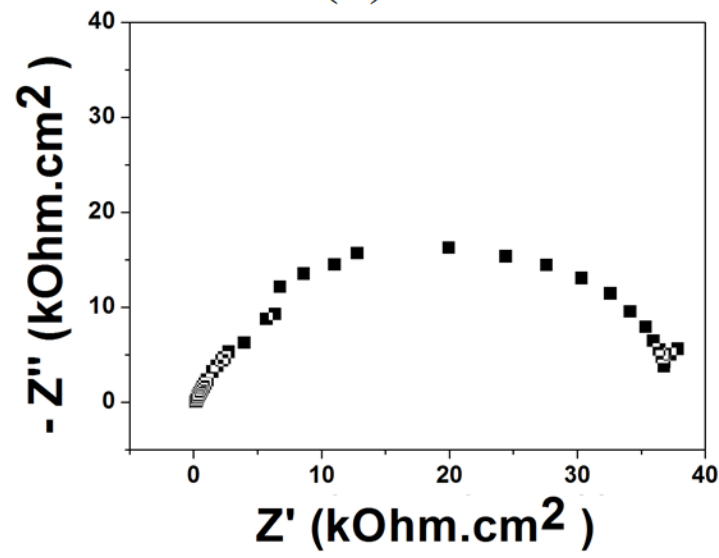

(C)

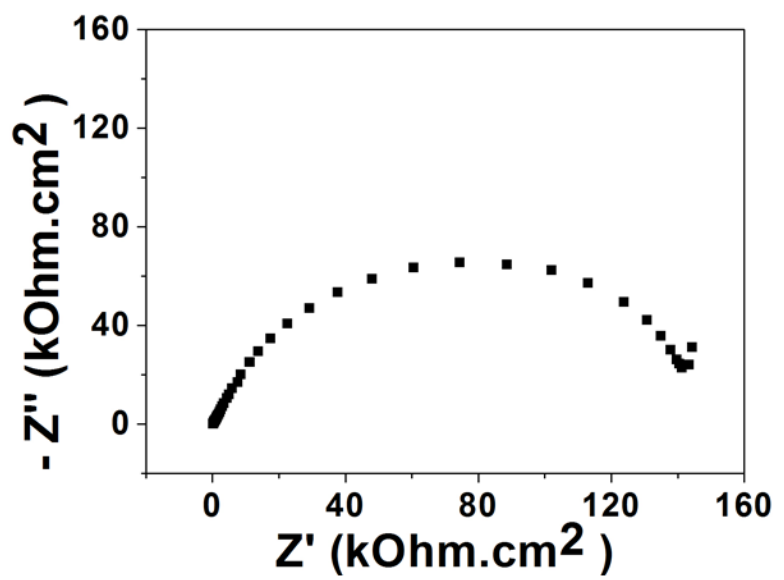

(B)

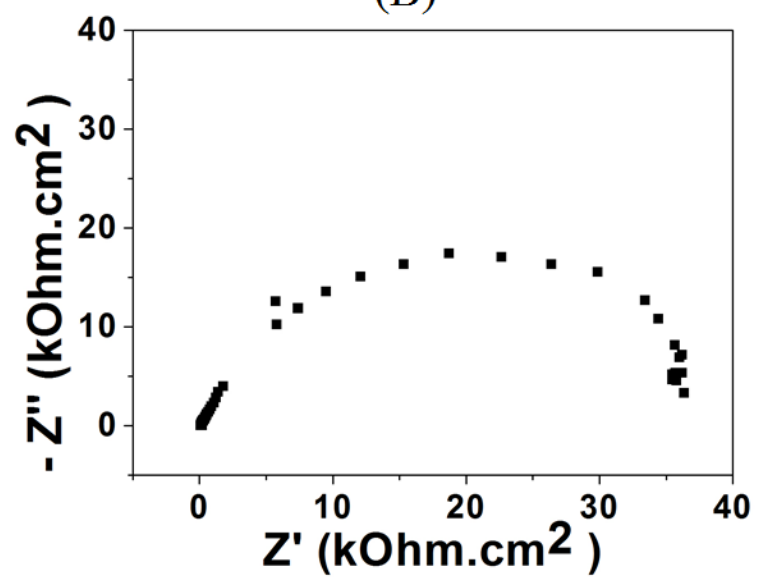

(D)

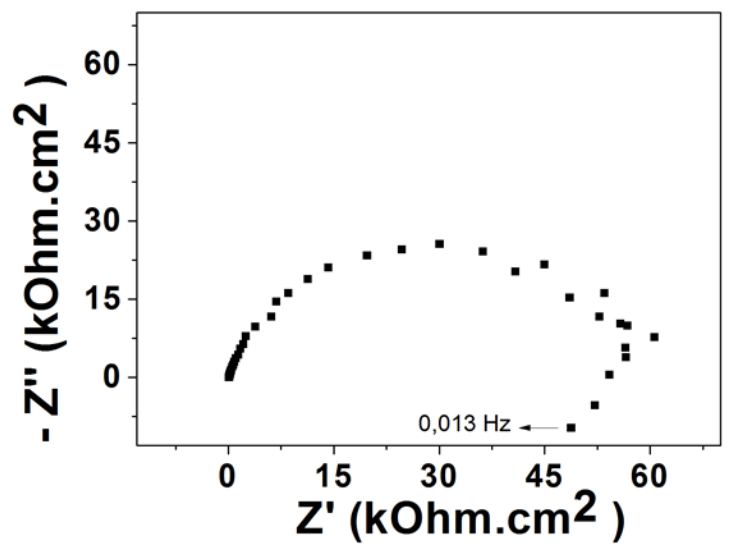

Figure 2. 2024-T3 aluminum alloy Nyquist diagrams after 3 days of immersion in $0.025 \mathrm{~mol} \cdot \mathrm{L}^{-1} \mathrm{NaCl}$ with differents anthocyanin concentrations (A) 0, (B) 800, (C) 1000 and (D) $2000 \mathrm{ppm}$.

Table 2 shows the EIS spectra with 3 days of immersion time in $0.025 \mathrm{~mol} \cdot \mathrm{L}^{-1} \mathrm{NaCl}$ solution containing $1000 \mathrm{ppm}$ of antocyanins of AA2024-T3 analyzed by equivalent circuits (EC). The equivalent circuit with two time constants that was tried to reproduce the results was $R_{\mathrm{s}}\left(Q_{\mathrm{HF}}\left[R_{\mathrm{HF}}\left(Q_{\mathrm{LF}} R_{\mathrm{LF}}\right]\right)\right]$ ) (see fitted parameters in Table 2). In this EC $R_{\mathrm{s}}$ corresponds to solution resistance, $Q_{\mathrm{HF}}$ and $Q_{\mathrm{LF}}$ are attributed to the oxide layer capacitance and oxide layer with adsorbed anthocyanin capacitance, respectively. $R_{\mathrm{HF}}$ and $R_{\mathrm{LF}}$ are associated with oxide layer resistance and oxide layer with adsorbed anthocyanin resistance. The constant phase element (CPE or $Q$ ), which substitutes the capacitance, was 
included in order to take into account phenomena related to the surface roughness and to diffusion processes, the capacitance was replaced by CPE impedance which is given by $Z_{\mathrm{CPE}}=\left[Q(\mathrm{j} \omega)^{n}\right]^{-1}$.

Table 2. Fitted parameters of equivalent circuits of EIS measurements of AA2024-T3 immersed by 3 days in solution containing $1000 \mathrm{ppm}$ of grape antocyanins and $0.025 \mathrm{~mol} \cdot \mathrm{L}^{-1} \mathrm{NaCl}$.

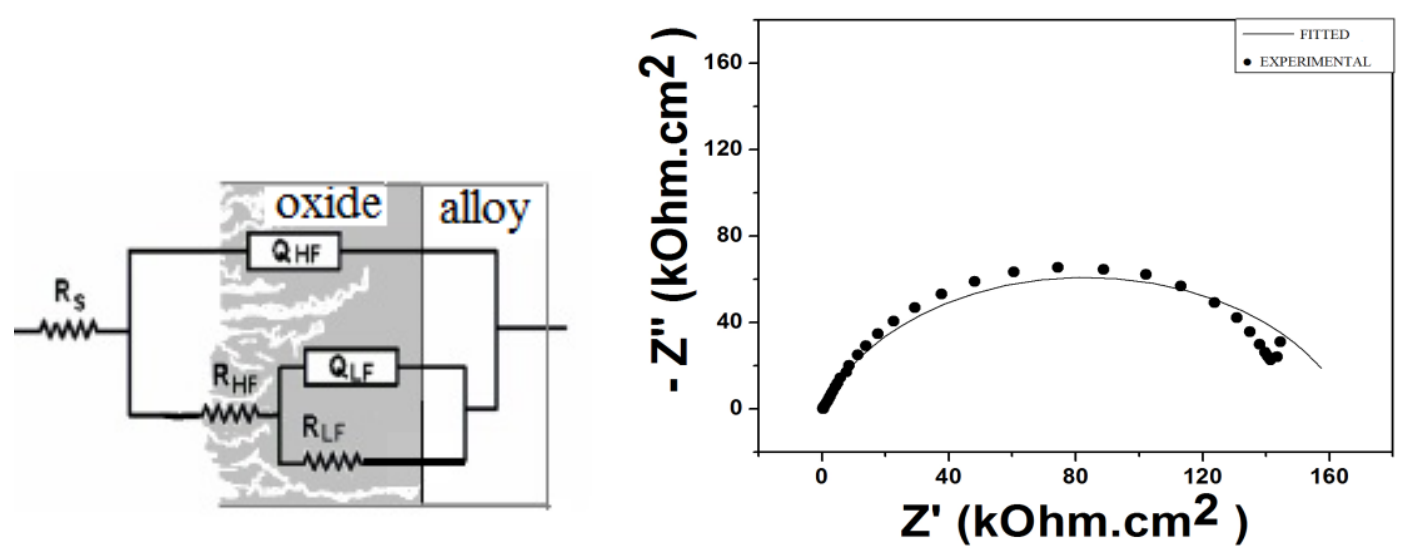

\begin{tabular}{cccccccc}
\hline $\begin{array}{c}\text { Concentration } \\
\text { of grape } \\
\text { antocyanins }\end{array}$ & $\begin{array}{c}\boldsymbol{R}_{\mathrm{S}} \\
\left(\mathbf{O h m} \cdot \mathbf{c m}^{2}\right)\end{array}$ & $\begin{array}{c}\boldsymbol{R}_{\mathrm{HF}} \\
\left(\mathbf{k O h m} \cdot \mathbf{c m}^{2}\right)\end{array}$ & $\begin{array}{c}\boldsymbol{Q}_{\mathrm{HF}} \\
\left(\boldsymbol{\mu} \mathbf{F} \cdot \mathbf{c m}^{-2}\right)\end{array}$ & $\boldsymbol{n}$ & $\begin{array}{c}\boldsymbol{Q}_{\mathrm{LF}} \\
\left(\mu \mathbf{F} \cdot \mathbf{c m}^{-2}\right)\end{array}$ & $\begin{array}{c}\boldsymbol{R}_{\mathrm{LF}} \\
\left(\mathbf{k O h m} \cdot \mathbf{c m}^{2)}\right.\end{array}$ & $\boldsymbol{n}$ \\
\hline $1000 \mathrm{ppm}$ & 330.50 & 91.10 & 0.67 & 0.8 & 7.30 & 74.30 & 0.8 \\
\hline
\end{tabular}

For the AA2024-T3 immersed in the solution containing $0.025 \mathrm{~mol} \cdot \mathrm{L}^{-1} \mathrm{NaCl}$ in the absence of antocyanins ( 0 ppm of antocyanins) only one capacitive loop is clearly visible in the Nyquist diagram; associated with the oxide layer $\left(R_{2}=39.3 \mathrm{k} \Omega \cdot \mathrm{cm}^{2}, Q_{1}=16.1\right.$ $\left.\mu \mathrm{F} \cdot \mathrm{cm}^{-2}\right)$, and with the diffusion process in the oxide layer $\left(Z_{\mathrm{w}}=2.5 \mathrm{kOhm} \cdot \mathrm{cm}^{2} \cdot \mathrm{s}^{1 / 2}\right)(\mathrm{see}$ fitted parameters in Table 3 ).

The potential change of $-510 \mathrm{mV}$ to $-581 \mathrm{mV}$ and the values of polarization resistance at $10 \mathrm{mHz}$ increases from $31.31 \mathrm{kOhm} \cdot \mathrm{cm}^{2}$ to $144.42 \mathrm{kOhm} \cdot \mathrm{cm}^{2}$, probably due to the adsorption process of anthocyanin on surface alloy (compare Table 2 and 3). The displacement in the corrosion potential suggests that the adsorption is not only a geometric blocking effect, which decreases the available reaction area for adsorption on the metal surface. The observed results indicate that anthocyanins modify the activation energy of the corrosion reactions [22]. 
Table 3. Fitted parameters of equivalent circuits of EIS measurements of AA2024-T3 immersed by 3 days in solution containing $0.025 \mathrm{~mol} \cdot \mathrm{L}^{-1} \mathrm{NaCl}$.

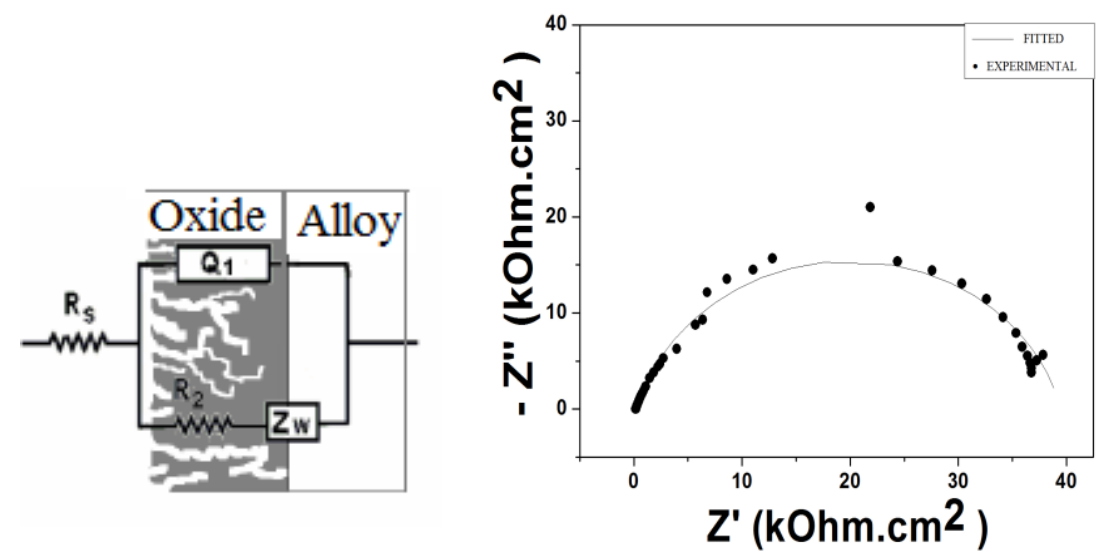

\begin{tabular}{cccccc}
\hline $\begin{array}{c}\text { Concentration of } \\
\text { grape antocyanins } \\
(\mathbf{p p m})\end{array}$ & $\begin{array}{c}\boldsymbol{R}_{\mathrm{s}} \\
\left(\mathbf{O h m} \cdot \mathbf{c m}^{2}\right)\end{array}$ & $\begin{array}{c}\mathbf{R}_{\mathbf{2}} \\
\left(\mathbf{k O h m} \cdot \mathbf{c m}^{2)}\right.\end{array}$ & $\begin{array}{c}\boldsymbol{Q}_{1} \\
\left(\boldsymbol{\mu} \mathbf{F} \cdot \mathbf{c m}^{-2}\right)\end{array}$ & $\boldsymbol{n}$ & $\begin{array}{c}\boldsymbol{Z}_{\mathrm{w}} \\
\left(\mathbf{k O h m} \cdot \mathbf{c m}^{2} \cdot \mathbf{s}^{\mathbf{1}}\right)\end{array}$ \\
\hline 0 & 169.9 & 39.3 & 16.1 & 0.8 & 2.5 \\
\hline
\end{tabular}

Table 4 shows the EIS spectra of AA2024-T3 with 3 days of immersion time in $0.025 \mathrm{~mol} \cdot \mathrm{L}^{-1} \mathrm{NaCl}$ solution containing 800 and $2000 \mathrm{ppm}$ of antocyanins analyzed by equivalent circuits (EC). The EC with one time constants tried to reproduce the results was $R_{\mathrm{s}}\left(Q_{1} R_{2}\right)$ (see fitted parameters in Table 4$)$. The EC with a one time constant tried to reproduce the results was $R_{\mathrm{S}}$ corresponds to solution resistance, $Q_{1}$ is attributed to the oxide layer capacitance and $R_{2}$ is attributed to oxide layer resistance.

The potentiodynamic polarization curves for aluminum alloy in $0.025 \mathrm{~mol} \cdot \mathrm{L}^{-1} \mathrm{NaCl}$ solution in the absence and presence of $1000 \mathrm{ppm}$ of anthocyanin are shown in Figure 3. The results mean that both anodic and cathodic reactions are suppressed in the presence of anthocyanin, i.e., there is a decrement of anodic dissolution and hydrogen production in cathodic zones. The $E_{\text {corr }}$ values for uninhibited and inhibited samples are $-620 \mathrm{mV}$ and $-510 \mathrm{mV}$, respectively, suggesting that it is a mixed type inhibitor with a predominantly anodic action [23]. 
Table 4. Fitted parameters of equivalent circuits of EIS measurements of AA2024-T3 immersed by 3 days in solution containing $0.025 \mathrm{~mol} \mathrm{~L}^{-1} \mathrm{NaCl}$ and different concentrations of grape antocyanins 800 and 2000 ppm.

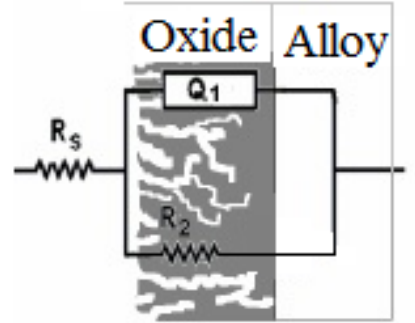

\section{Concentration of grape antocyanins (ppm) \\ $\begin{array}{cccc}R_{\mathrm{s}} & R_{2} & Q_{1} & n\end{array}$ \\ $\begin{array}{cccc}R_{\mathrm{s}} & R_{2} & Q_{1} & n\end{array}$ \\ $\begin{array}{cccc}R_{\mathrm{s}} & R_{2} & Q_{1} & n\end{array}$}

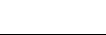

$8000141.5 \quad 39.0$




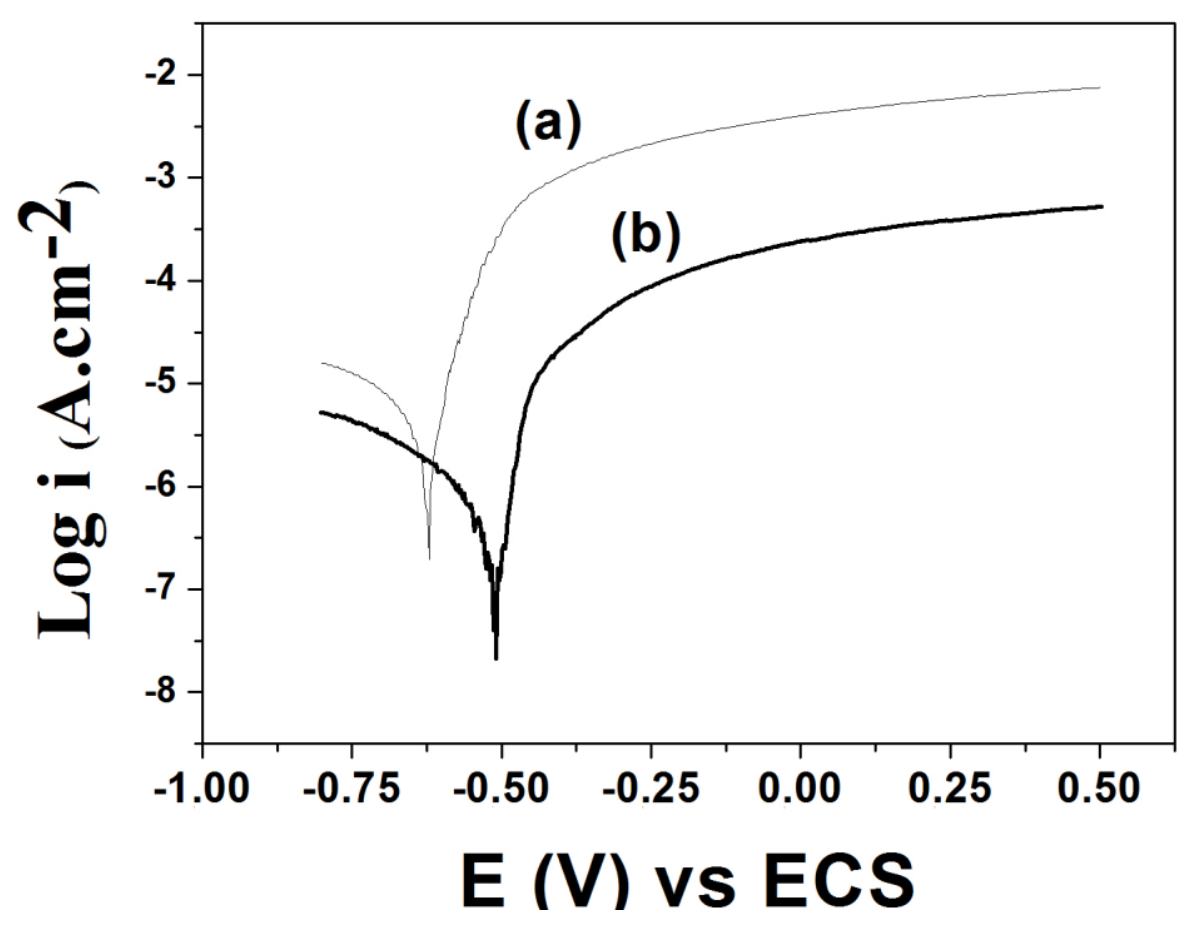

Figure 3. Anodic and cathodic polarization of 2024-T3 aluminum alloy after 3 days of immersion in $0.025 \mathrm{~mol} \cdot \mathrm{L}^{-1} \mathrm{NaCl}$ with differents anthocyanin concentrations (a) 0 and (b) $1000 \mathrm{ppm}$.

\subsection{Adsorption isotherm}

The anthocyanin adsorption phenomenon on aluminum alloy surface can be quantitatively assessed by an adsorption isotherm, which models the adsorption amount on the metal surface and solution interface with the inhibitor concentrations in solution phase when the adsorption equilibrium has been achieved on the metal surfaces. The adsorbed anthocyanin amount $\left(Q_{\mathrm{e}}\right)$ for different concentrations of anthocyanin was calculated from UV-vis absorbance measurements. The observed changes in $Q_{\mathrm{e}}$ are shown in Table 5 as a function of anthocyanin concentration $\left(C_{\mathrm{e}}\right)$. The plot $1 / Q_{\mathrm{e}}$ versus $1 / C_{\mathrm{e}}$ (Figure $4 \mathrm{a}$ ) was analyzed in order to evaluate the adsorption process according to the Langmuir isotherms - equation (4):

$$
\frac{1}{Q_{\mathrm{e}}}=\frac{1}{Q_{\max }}+\frac{1}{Q_{\max } \cdot k_{\mathrm{L}}} \times \frac{1}{C_{\mathrm{e}}}
$$

where $Q_{\mathrm{e}}$ is the amount of anthocyanins adsorbed by adsorbate weight $\left(Q_{\mathrm{e}}\right)$ in equilibrium; $C_{\mathrm{e}}$ is the anthocyanin solution concentration in equilibrium; $k_{\mathrm{L}}$ is the adsorption equilibrium constant and $Q_{\max }$ is the maximum quantity of anthocyanin adsorbed by the solid adsorbate weight (aluminum alloy panels). 
Table 5. $Q_{\mathrm{e}}, 1 / Q_{\mathrm{e}}, 1 / C_{\mathrm{e}}, \operatorname{Ln} Q_{\mathrm{e}}$ and $\operatorname{Ln} C_{\mathrm{e}}$ data used for adsorption characteristics study of grape anthocyanins on AA2024-T3.

\begin{tabular}{ccccc}
\hline $\begin{array}{c}\boldsymbol{Q}_{\mathrm{e}} \\
(\mathbf{p p m} / \mathbf{g})\end{array}$ & $\begin{array}{c}\mathbf{1} / \boldsymbol{Q}_{\mathrm{e}} \\
\left(\mathbf{g} / \mathbf{p p m} \times \mathbf{1 0}^{-\mathbf{3}}\right)\end{array}$ & $\begin{array}{c}\mathbf{1} / \boldsymbol{C}_{\mathrm{e}} \\
\left(\mathbf{p p m}^{-\mathbf{1}} \times \mathbf{1 0}^{-\mathbf{3}}\right)\end{array}$ & $\mathbf{L n} \boldsymbol{Q}_{\mathrm{e}}$ & $\mathbf{L n} \boldsymbol{C}_{\mathrm{e}}$ \\
\hline 0 & & & & 4.60 \\
6.04 & 165.60 & 10.00 & 1.80 & 5.87 \\
20.93 & 47.7 & 2.82 & 3.04 & 6.68 \\
46.57 & 21.50 & 1.30 & 3.84 & 6.91 \\
84.86 & 11.80 & 1.00 & 4.44 & 7.60 \\
316.43 & 3.20 & 0.50 & 5.76 & 8.01 \\
645.81 & 1.50 & 0.30 & 6.47 & 8.52 \\
659.87 & 1.50 & 0.20 & 6.49 & 8.89 \\
443.04 & 2.30 & 0.14 & 6.09 & \\
\hline
\end{tabular}

(A)

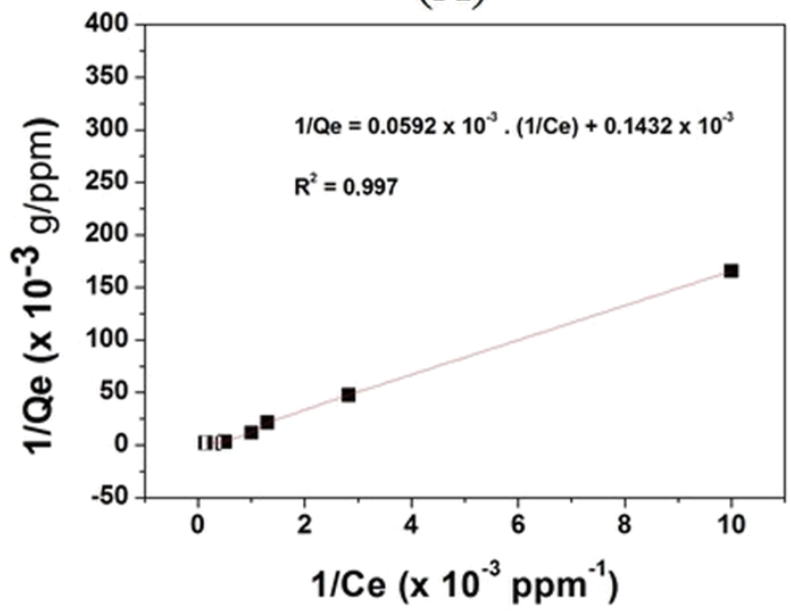

(B)

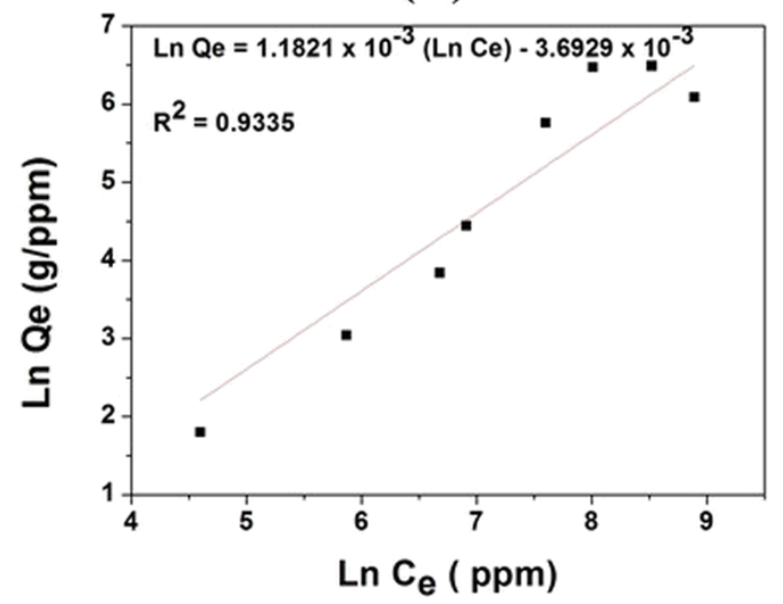

Figure 4. $1 / Q_{\mathrm{e}}$ versus $1 / C_{\mathrm{e}}(\mathrm{A})$ and $\operatorname{Ln} Q_{\mathrm{e}}$ versus $\operatorname{Ln} C_{\mathrm{e}}(\mathrm{B})$ graphics.

The $\operatorname{Ln} Q_{\mathrm{e}}$ versus $\operatorname{Ln} C_{\mathrm{e}}$ graphic (Figure $4 \mathrm{~b}$ ) was also analyzed in order to evaluate the adsorption process according to Freundlich isotherm by equation (5):

$$
\text { Ln } Q_{\mathrm{e}}=\operatorname{Ln} k_{\mathrm{F}}+n \cdot \ln C_{\mathrm{e}}
$$

where $Q_{\mathrm{e}}$ is the amount of anthocyanin adsorbed by adsorbate weight $\left(Q_{\mathrm{e}}\right)$ in the equilibrium; $k_{\mathrm{F}}$ is the adsorption constant; $n$ is the empiric parameter that is positive and lower than $1 ; C_{\mathrm{e}}$ is the anthocyanin solution concentration in equilibrium.

The linear plots obtained in Figure 4a suggest that the adsorption characteristics of the inhibitor were approximated by Langmuir isotherm $\left(\mathrm{R}^{2}=0.997\right)$. 
Considering that $\Delta G=-R T \operatorname{Ln} K_{\mathrm{d}}$, where $K_{\mathrm{d}}$ is the equilibrium constant for adsorption [24] which is evaluated from plots $Q_{\mathrm{e}} / C_{\mathrm{e}}$ versus $Q_{\mathrm{e}}$ extrapolating $Q_{\mathrm{e}}$ to zero (data not shown), the $K_{\mathrm{d}}$ is equal to $0.0003 \mathrm{ppm} \cdot \mathrm{g}^{-1}$ and $\Delta G$ is equal to $-20.1 \mathrm{~kJ} \cdot \mathrm{mol}^{-1}$. These values indicate that the antocyanins adsorption on AA2024-T3 is a spontaneous and favorable process.

The effectiveness of the adsorption anthocyanin on aluminum alloy surface in chloride solution can be attributed to the presence of the aromatic group and $\mathrm{O}$-atom in the molecules. Moreover, at solution $\mathrm{pH} 6$ the anthocyanin is charged negatively as a quinodal base [25]. On the other hand, the aluminum surface is lower than the isoelectric point when there is a positive charge present. In this way, the anthocyanin could interact with the metal via electrostatic coulomb attractive forces. Another possibility is the adsorption of anthocyanin molecules on the aluminum alloy surface as aggregates. The last model was proposed by Mobin et al. to explain the corrosion inhibition effect observed for amino acid L-methionine and sodium dodecyl sulfate on mild steel [26]. Nevertheless, the good fit to the Langmuir isotherm indicates that no interactions occur between adsorbed anthocyanin molecules)

\subsection{Surface Analysis}

The AA2024-T3 alloy surface after 3 days of immersion into $0.025 \mathrm{~mol} \cdot \mathrm{L}^{-1} \mathrm{NaCl}$ solution in the absence (Figure 5) and presence of $1000 \mathrm{ppm}$ anthocyanins (Figure 6) were observed by Scanning electron microscopy images with EDS analysis (inserted into Figures 5 and 6 , respectively). It can be noted that the morphology of surficial deposits is different in both images. Besides, the $\mathrm{Al} / \mathrm{Cl}$ ratio of the sample in chloride solution and in anthocyanincontaining solution is 31 and 2.3, respectively. These features indicate that for uninhibited panels the corrosion products are deposited in specific regions on the alloy surface and corresponding to oxychlorides. Concerning the SEM/EDS inhibited panels results it could be mentioned that the thick springy layer is probably a mixture between adsorbed anthocyanin film on the alloy surface and corrosion products. A plausible explanation for these corrosion products is that they are formed by oxychlorides and metal-complexes, due to the anthocyanin capacity of metal chelating as verified by Wang et al. [27].

The AFM technique is a powerful tool to check the corrosion process at the metal/solution interface [28]. The three-dimensional AFM images of aluminum alloy specimens after immersion for 3 days in $0.025 \mathrm{~mol} \cdot \mathrm{L}^{-1} \mathrm{NaCl}$ solution containing or not $1000 \mathrm{ppm}$ anthocyanin are depicted in Figures 7 and 8, respectively. It is clearly perceived that the rough structure of alloy surface exposed to chloride solution (Figure 8-a), presents topographic variations between peaks and valleys of about $460 \mathrm{~nm}$. With the addition of $1000 \mathrm{ppm}$ anthocyanin the surface becomes rougher (Figure 8) with height fluctuation within $670 \mathrm{~nm}$. The average roughness $\left(R_{\mathrm{a}}\right)$ of the unprotected and protected aluminum alloy surface is $81 \mathrm{~nm}$ and $169 \mathrm{~nm}$, respectively. These superficial observations combined with the electrochemical analysis suggest that anthocyanin could act as an effective corrosion adsorption inhibitor for 2024-T3 aluminum alloy. 


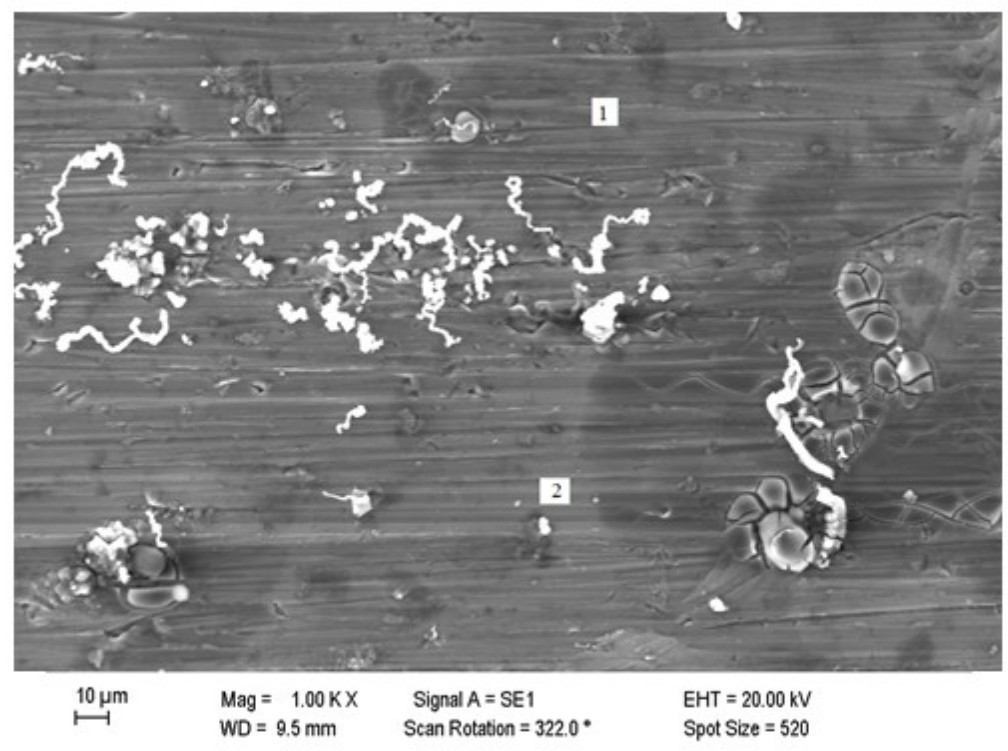

Region 1

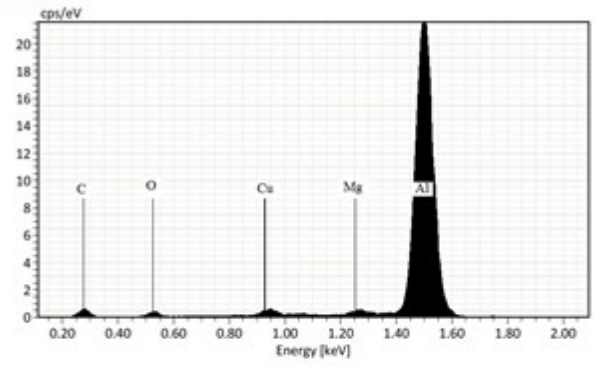

Region 2

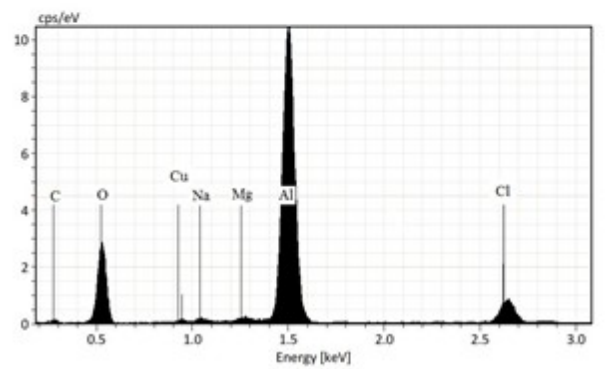

Figure 5. Scanning electron microscopy images with EDS analysis of the AA2024-T3 alloy surface after 3 days of immersion into $0.025 \mathrm{~mol} \cdot \mathrm{L}^{-1} \mathrm{NaCl}$ solution.
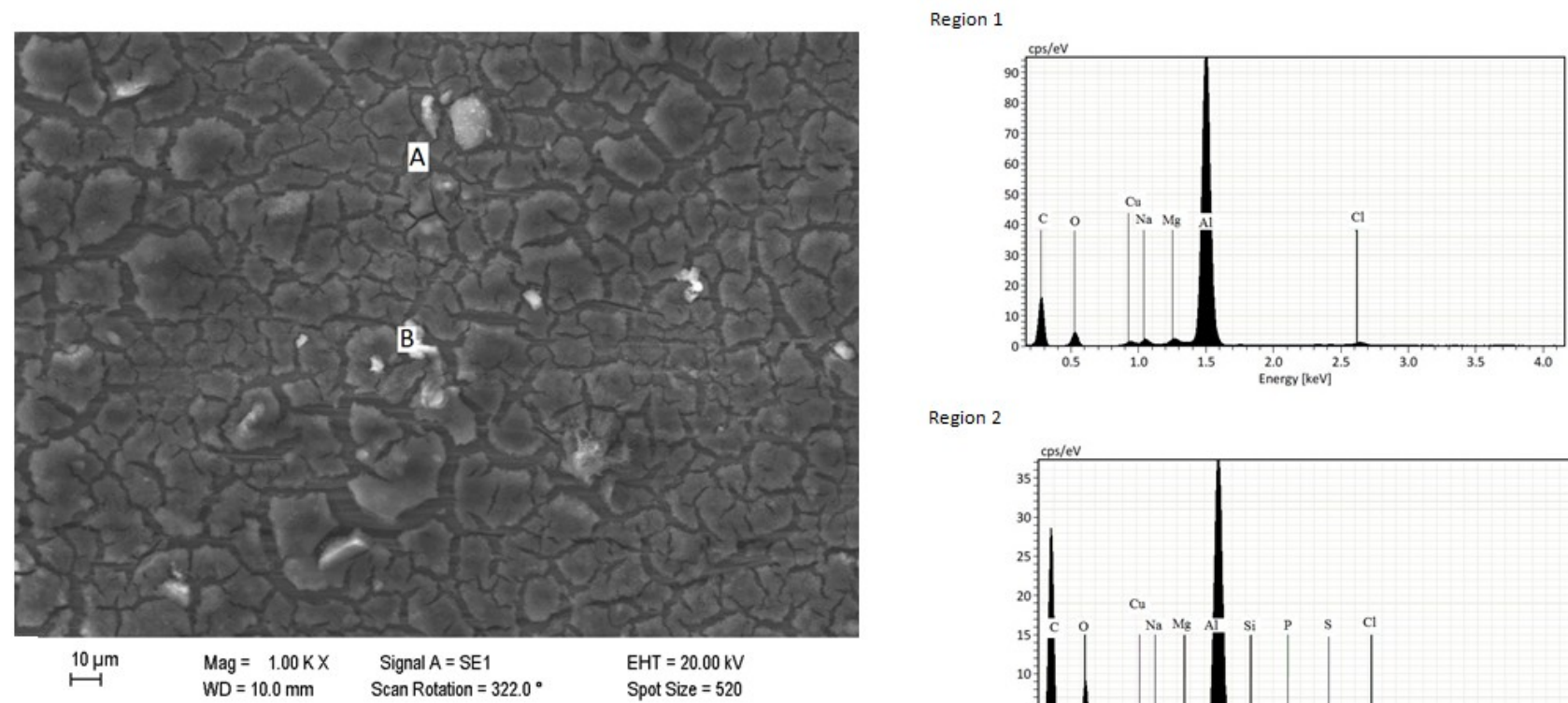

Region 2

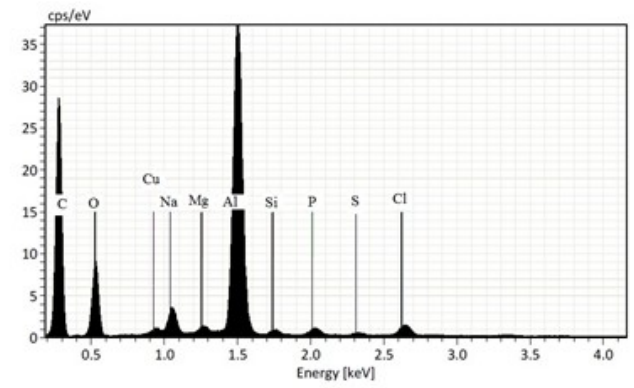

Figure 6. Scanning electron microscopy images with EDS analysis of the AA2024-T3 alloy surface after 3 days of immersion into $0.025 \mathrm{~mol} \cdot \mathrm{L}^{-1} \mathrm{NaCl}$ solution containing $1000 \mathrm{ppm}$ of anthocyanin. 


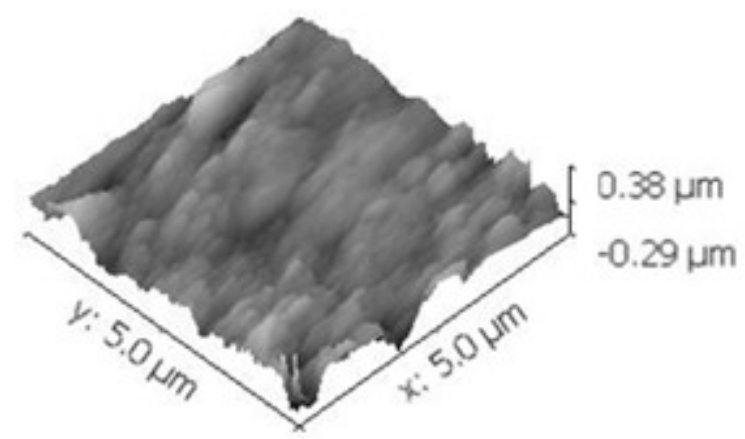

Region 1

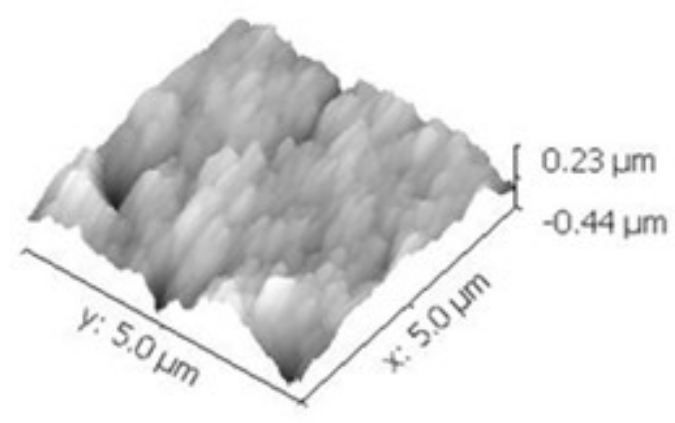

Region 2

Figure 7. AFM images of AA2024-T3 aluminum alloy after immersion for 3 days in $0.025 \mathrm{~mol} \cdot \mathrm{L}^{-1} \mathrm{NaCl}$ solution containing $1000 \mathrm{ppm}$ anthocyanin.

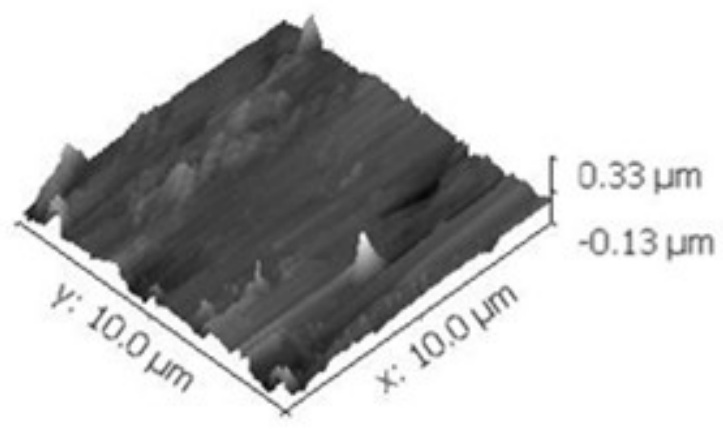

Region 1

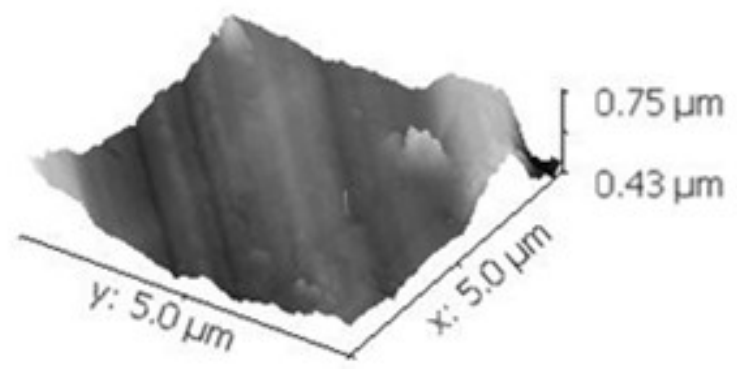

Region 2

Figure 8. AFM images of AA2024-T3 aluminum alloy after immersion for 3 days in $0.025 \mathrm{~mol} \cdot \mathrm{L}^{-1} \mathrm{NaCl}$ solution. 


\section{Conclusions}

Grape anthocyanins meet the requirement for an environmentally friendly corrosion inhibitor because of their low toxicity, biodegradability and availability. Furthermore, they present good efficiency for protection against corrosion of aluminum alloy 2024-T3. The adsorption characteristics of the antocyanins were approached by Langmuir isotherm and the good anticorrosive properties are attributed to their good adsorption capacity.

\section{Acknowledgment}

Teacher Alexandre Englert, Marina Ginity, Capes and CNPq for financial assistance.

\section{References}

1. E.E. Oguzie, Corros. Sci., 2007, 49, 1527.

2. E.A. Noor, J. Appl. Electrochem., 2009, 39, 1465.

3. B.E.A. Rani and B.B.J. Basu, Int. J. Corros., 2012, 1, 1.

4. A.Y. El-Etre, Corros. Sci., 2003, 45, 2485.

5. K. Shalabi, A.S. Fouda and G.Y. Elewady, Prot. Met. Phys. Chem. Surf., 2014, 50, 420.

6. D.I. Njoku, G.N. Onuoha, E.E. Oguzie, K.L. Oguzie, A.A. Egbedina and A.N. Alshawabkeh., Arab. J. Chem., 2016, doi: 10.1016/j.arabjc.2016.07.017

7. N.O. Obi-Egbedi, I.B. Obot and S.A. Umoren, Arab. J. Chem., 2012, 5, 361.

8. E. Baran, A. Cakir; B. Yazici, Arab. J. Chem., 2016, doi: 10.1016/j.arabjc.2016.06.008

9. E.E. Oguzie, C.K. Enenebeaku, C.O. Akalezi, S.C. Okoro, A.A. Ayuk and E.N. Ejike, J. Colloid Interface Sci., 2010, 349, 283.

10. A. Castañeda-Ovando, Ma. de Lourdes Pacheco-Hernández, Ma. E. Páez-Hernández J.A. Rodríguez and C.A. Galán-Vidal, Food Chem., 2009, 113, 859.

11. P.H. Março, Química Nova, 2008, 31, 1218.

12. P. Markakis, Anthocyanins as food colors, Academic Press, New York, 1982.

13. D.C. Harris, Quantitative Chemical Analysis, LTC, Rio de Janeiro, 2005.

14. M.E. Orazem and B. Tribollet, Electrochemical Impedance Spectroscopy, John Wiley, New Jersey, 2008.

15. C.M.A. Brett, Corros. Sci., 1992, 33, 203.

16. H.J.W. Lenderink, M.V.D. Linden and J.H.W. De Wit, Electrochim. Acta., 1993, 38, 1989.

17. D. Zhu and W.J.V. Ooij, Corros. Sci., 2003, 45, 2177.

18. S.A. Umoren, I.B. Obot, E.E. Ebenso and N.O. Obi-Egbedi, Desalination, 2009, 247, 561.

19. Z. Minyan and W. Yongsheng, Natural Product Research and Development, 2003, 15, 494.

20. T. Tahanashi, Chem. Pharm. Bull., 2000, 48, 1200. 
21. V. Dalmoro, J. H.Z. dos Santos, E. Armelin, C. Aleman and D.S. Azambuja A., Appl. Surf. Sci., 2013, 273, 758.

22. S. Martinez and M. Metikoš-Huković, Int. J. Corros., 2003, 33, 1137.

23. H.M. Abd El-Lateef, Corros. Sci., 2015, 92, 104.

24. O. Hamdaoui and E. Naffrechoux, J. Hazard. Mater., 2007, 147, 401.

25. R. Brouillard and J. Lang, Can. J. Chem., 1990, 68, 755.

26. M. Mobin, M. Parveen and M.Z.A. Rafiquee, Arab. J. Chem., 2017, doi: 10.1016/j.arabjc.2013.04.006

27. H. Wang, M.G. Nair, G.M. Strasburg, Y.C. Chang, A.M. Booren, J.I. Gray and D.L. DeWitt, J. Nat. Prod., 1999, 62, 294.

28. G. Ji, S. Anjum, S. Sundaram and R. Prakash, Corros. Sci., 2015, 90, 107. 